\title{
A Laboratory Approach to Measure Carbonate Rocks' Adsorption Density by Surfactant and Polymer
}

\author{
Hamid Esfandyari $\mathbb{D}^{1},{ }^{\text {Abdorrahman Moghani, }}{ }^{1}$ Feridun Esmaeilzadeh $\mathbb{D}^{2}{ }^{2}$ \\ and Afshin Davarpanah $\mathbb{D}^{3}$ \\ ${ }^{1}$ Department of Petroleum Engineering, Abadan Faculty of Petroleum Engineering, Petroleum University of Technology (PUT), \\ Abadan, Iran \\ ${ }^{2}$ Department of Chemical and Petroleum Engineering, School of Chemical and Petroleum Engineering, \\ Enhanced Oil and Gas Recovery Institute, Enhanced Gas Condensate Recovery Research Group, Shiraz University, Shiraz, Iran \\ ${ }^{3}$ Department of Petroleum Engineering, Science and Research Branch, Islamic Azad University, Tehran, Iran \\ Correspondence should be addressed to Hamid Esfandyari; esfandyari_shirazu@yahoo.com
}

Received 9 January 2021; Revised 3 February 2021; Accepted 8 February 2021; Published 18 February 2021

Academic Editor: Mohammad Yazdi

Copyright (c) 2021 Hamid Esfandyari et al. This is an open access article distributed under the Creative Commons Attribution License, which permits unrestricted use, distribution, and reproduction in any medium, provided the original work is properly cited.

\begin{abstract}
Chemical recovery techniques have always been considered as one of the efficient secondary and tertiary recovery methods to enhance the oil recovery factor. Regarding the diversity of reservoir heterogeneity and rock properties for each field, various chemical agents were taken into consideration to provide a feasible process that has the best agreement with the reservoir characterization. The objective of this paper is to investigate the considerable influence of a set of chemical agents and temperature impact on the surfactant adsorption density of carbonate rocks. According to the results of this experiment, higher temperatures provide lower surfactant adsorption density. The lowest adsorption carbonate rocks' adsorption density had occurred at $80^{\circ} \mathrm{C}$. Furthermore, it was witnessed that hydrolyzed polyacrylamide addition to the surfactant would cause a dramatic decrease in the adsorption density in comparison with the surfactant or polymer individually.
\end{abstract}

\section{Introduction}

Nowadays, many kinds of research studies have been complimented on the tertiary oil recovery field in order to enhance oil recovery (EOR) and make stable oil production after the primary and secondary oil recovery [1-7]. The use of a surfactant as a surface-active agent is one of the new techniques for growing oil extraction by changing the wettability of carbonate reservoirs from oil-wet to water-wet [8-13]. This chemical agent, by reducing IFT and/or altering surface wettability, causes the movement of trapped oils to boost and so to enhance oil recovery [14-18]. In recent decades, chemical injections have been extensively used in enhancing oil recovery, aiming at increasing the displacement coefficient in heterogeneous reservoirs and hence reducing residual oil saturation [19-24].
In petroleum engineering, the polymer is used as an additive in the petroleum reservoir to sweeping oil to increase oil recovery. Chemical flooding has subcategories such as polymer flooding, surfactant flooding, alkali/polymer flooding, and alkali/surfactant/polymer (ASP) flooding [25-31].

Injection of a surfactant and/or a polymer is one of the essential chemical injection mechanisms, especially in reservoirs with high water salinity in which alkaline is not suggested due to the deposition of salty compounds in the formation. ASP flooding can improve oil production more than water flooding noticeably; however, it causes new problems due to the attendance of high amount of alkali, for instance, the mixture of the oil-in-water emulsion has harmful effects of the shell and the corrosion of the oil production tools [32-35]. Therefore, the new surfactant 
combinations without alkali are of crucial importance in the EOR process, particularly in oil reservoirs with high temperature gradient and high salinity. In this method, the surfactant can be used for two reasons: decreasing the interfacial tension between water and oil and changing rock wettability [36-39]. Additionally, using the polymer can be exploited to reduce the water and oil mobility ratio. Since a surfactant enables to bond with the strands of a polymer, the combination of surfactants and polymers creates different properties and performances than when used individually $[17,40]$.

Ahmed et al. (2014) evaluated the adsorption of a cationic surfactant, namely, C12 on carbonate minerals. They investigated the adsorption of this surfactant in carbonate formations and stated that its adsorption ability depends on different parameters including $\mathrm{pH}$, electrolyte composition of formation water, and mineral types present in carbonate formations. The amount of its adsorption on calcite at a low level of $\mathrm{pH}(5-6.5)$ is $0.5 \mathrm{mg} / \mathrm{m}^{2}$. However, the adsorption capacity increases when carbonate formations possess silica or clay compounds. Wang et al., in 2015, worked on the adsorption of chemical surfactants on carbonate reservoirs via the injection of the surfactant/polymer in three ways: injection of the surfactant alone, injection of the polymer after the surfactant, and injection of the polymer and surfactant together. They used Betaine, an amphoteric surfactant, and hydrolyzed polyacrylamide polymer sulphonate. Results showed that the adsorption capacity of the carbonate rock was found to be $0.163 \mathrm{mg} / \mathrm{g}$ of the rock, during surfactant flooding alone, and if the injection of the surfactant along with the polymer would be fulfilled, the average capacity of adsorption was found to be $0.079 \mathrm{mg} / \mathrm{g}$ of the rock; otherwise, when the combination of the surfactant and polymer was injected, the average capacity of adsorption would be $0.083 \mathrm{mg} / \mathrm{g}$ of the rock [41]. Feng et al. in 2012 stated that the mixture of the polymer to the surfactant solution accelerated the reduction of surface tension between water and oil. They showed that the injection of chemicals containing polymer and alkaline led to increasing the oil recovery rate from $13 \%$ to $20 \%$. This value is much larger than that when the injection of the polymer was applied alone under the same conditions [17].

Ahmed F. Belhaj et al. (2021) investigated the adsorption behavior of two chemical surfactant nanionic alkyl polyglucoside (APG) and anionic alkyl ether carboxylate (AEC) on the carbonate surfactant using static adsorption experiments and artificial neural network (ANN) prediction. The static experiment indicated that the nanionic surfactant has more adsorption density with respect to the anionic surfactant. The ANN model revealed good agreement with the experimental result, and also, the results showed that adsorption density for both surfactants decreases as temperature increases [42]. Das et al. (2020) measured the adsorption density of a nanionic surfactant with two different types of hydrophobic units and hydrophilic polyethoxylate units ranging from 15 to 40 mers on Indiana limestone. The results showed that adsorption increased by temperature increasing and decreased with more hydrophilic groups [43]. Saha et al. (2017) investigated the effect of mineralogy on the adsorption characteristics of the surfactant-reservoir rock system. Cationic Triton X-100 was used as the chemical surfactant, and the results indicated that adsorption capacity of the surfactant is strongly dependent on the mineral content of the rock in the order of illite $>$ feldspar $>$ montmorillonite $>$ kaolinite [44]

The adsorption and preservation of polymers and surfactants on reservoir rock surfaces are notable factors in the injection process due to decreasing fluid viscosity, leading to the reduction of final oil recovery. This indicates loss of chemicals from the solution and hence reduction in the amount of chemical injection. Executive and, especially, economic aspects can influence the efficiency of chemical injection operation. Therefore, the lower the absorption of the polymer and surfactant is, the lower the amount of the injectable chemical and final cost would be. Since surfactants have a high potential to reduce the surface tension between water and oil and to change the wettability of the rocks to water-wetting, the main objectives of this study are as follows:

(i) Investigation of the adsorption ability of different concentrations of Triton X-100 as a surfactant on a carbonate rock

(ii) Investigation of the impact of using the hydrolyzed acrylamide polymer on the adsorption capacity of Triton X-100 in critical concentration

(iii) Investigation of the effect of temperature on the adsorption capacity of the assessed surfactant

\section{Materials and Methods}

The core plug used in experiments is from the Binak oil field located in the south of Iran. The properties of the used core plug are given in Table 1.

The aqueous phase used in this study includes distilled water along with sodium chloride with the concentration of $10,000 \mathrm{ppm}$. The Triton X-100 is a nonionic surfactant with a water-wet polyethene oxide chain (5 units of ethylene oxide) and an aromatic lipophilic or hydrophobic chain and was created by Merck Company. The general properties of this material are given in Table 2.

Nonionic polyacrylamide provides a neutral solution when solved in distilled water. Table 3 and Figure 1 show the characteristics and form of this compound, respectively.

2.1. Experimental Method. The experimental procedure which was done in this investigation is as follows:

(1) Cleaning the core plug in a soxhlet by combining toluene and methanol

(2) Drying the core in the oven and powdering it with milling

(3) Prepare different concentrations of Triton X-100 (50-1000 ppm) and polymer $(250-2500 \mathrm{ppm})$ in a brine solution with a concentration of $10000 \mathrm{ppm}$

(4) Separation of $3 \mathrm{gr}$ of the rock powder and mixing with $60 \mathrm{gr}$ of the surfactant and polymer solution 
TABLE 1: The properties of the used core sample.

\begin{tabular}{|c|c|c|c|c|c|c|}
\hline Material & $\begin{array}{l}\text { Porosity } \\
\text { (\%) }\end{array}$ & $\begin{array}{l}\text { Pore volume } \\
\left(\mathrm{cm}^{3}\right)\end{array}$ & $\begin{array}{l}\text { Absolute permeability } \\
\text { (md) }\end{array}$ & $\begin{array}{l}\text { Gas permeability } \\
(\mathrm{md})\end{array}$ & $\begin{array}{l}\text { Diameter } \\
(\mathrm{cm})\end{array}$ & $\begin{array}{l}\text { Length } \\
(\mathrm{cm})\end{array}$ \\
\hline Anhydrite + dolomite & 13.39 & 12.10 & 4.76 & 10.60 & 3.67 & 8.54 \\
\hline
\end{tabular}

TABLE 2: The chemical and physical characteristics of the used surfactant.

\begin{tabular}{lc}
\hline Chemical formula & $\mathrm{C}_{14} \mathrm{H}_{22} \mathrm{O}\left(\mathrm{C}_{2} \mathrm{H}_{4} \mathrm{O}\right) \mathrm{n}(n=9-10)$ \\
\hline Molecular weight & $647 \mathrm{gr} / \mathrm{mol}$ \\
Physical state & Viscous and colorless fluid \\
Density & $1.07 \mathrm{gr} / \mathrm{cm}^{3}$ \\
Melting point & $6^{\circ} \mathrm{C}$ \\
Vapour pressure & Less than $1 \mathrm{mmHg}$ \\
Flammability point & $251^{\circ} \mathrm{C}$ \\
\hline
\end{tabular}

Table 3: Properties of the used polymer.

\begin{tabular}{lc}
\hline Name & $\begin{array}{c}\text { Partially hydrolyzed } \\
\text { polyacrylamide }\end{array}$ \\
\hline Physical state & White granule powder \\
Solubility & Soluble in water \\
Molecular weight & $15-25 \mathrm{~g} / \mathrm{mol}$ \\
Insoluble impurities & $\%<2.0$ \\
Hydrolization degree & $20-30 \%$ \\
Solving time & Less than $60 \mathrm{~min}^{-}$ \\
Chemical formula & {$\left[-\mathrm{CH}_{2} \mathrm{CH}\left(\mathrm{CONH}_{2}\right)-\right]$} \\
Kind & Nonionic \\
Free monomers and partially & $\mathrm{Up} \mathrm{to} \mathrm{a} \mathrm{maximum} \mathrm{of}$ \\
hydrolyzed polyacrylamide & $0.05 \%$ \\
\hline
\end{tabular}

(5) Perform the adsorption test in different concentrations and different temperatures

(6) Measure CMC of the surfactant solutions and polymer by electrical conductivity and $\mathrm{pH}$

(7) Preparing CMC and retesting at 25, 40, 60, and $80^{\circ} \mathrm{C}$

(8) Adding polyacrylamide to the surfactant solution in CMC concentration and retesting in four different temperatures and salt concentration of $10000 \mathrm{ppm}$

(9) Evaluating the results and the curves and giving recommendations

\section{Results and Discussion}

The adsorption of the surfactant at the salt concentration of $10000 \mathrm{ppm}$ in different surfactant concentrations and four temperature ranges is primarily investigated. The critical concentration of the solutions containing Triton X-100 surfactant and hydrolyzed polyacrylamide is then calculated with $\mathrm{pH}$ and electrical conductivity methods, and their CMCs were used to perform adsorption tests.

3.1. Temperature Impact. The impact of temperature on the absorption capacity of the surfactant was examined at 25,40 , 60 , and $80^{\circ} \mathrm{C}$. In these experiments, $3 \mathrm{gr}$ of the powdered rock was placed in a beaker, and $60 \mathrm{~g}$ of the surfactant and brine solution with the concentration of $10000 \mathrm{ppm}$ was added. Ten experiments were conducted in 24 hours with different concentrations of the surfactant in the range of 50 to $1000 \mathrm{ppm}$. After 12 hours, the solution reached the equilibrium, and then, the adsorption density was measured using the following equation:

$$
\tau=\left(\frac{\left(C_{1}-C_{e}\right) * M_{s}}{M_{c}}\right) * 10^{-3}
$$

where $\tau$ is the adsorption density $(\mathrm{mg} / \mathrm{g}), C_{\mathrm{i}}$ is the initial concentration, $C_{\mathrm{e}}$ is the equilibrium concentration (ppm), $M_{\mathrm{s}}$ is the solution weight, and $M_{\mathrm{c}}$ is the rock powder weight (gr). The data obtained in the ambient temperature are illustrated in Figure 2. As to be seen in this graph, increasing the surfactant concentration elevates the adsorption density. The increasing rate was extremely ascending to $400 \mathrm{ppm}$ and remained fairly stable. Ultimately, the adsorption density would be $3.91 \mathrm{mg} / \mathrm{g}$ at this temperature.

Previous experiments were repeated at the same concentrations at $40^{\circ} \mathrm{C}$, and their results are shown in Figure 2. An increase of about $15^{\circ} \mathrm{C}$ has led to a decrease in density. As the data show, the concentration of the remaining surfactant in the solution has increased. The density of adsorption at this temperature has decreased to $3.556 \mathrm{mg} / \mathrm{g}$. The experiments were conducted at $60^{\circ} \mathrm{C}$, and the amount of surfactant remaining in the test container was slightly higher than that at $40^{\circ} \mathrm{C}$, which means that an increase of $20^{\circ} \mathrm{C}$ has been able to reduce the adsorption density. The data from the experiments are shown in Figure 2. The adsorption density is reduced to $3.44 \mathrm{mg} / \mathrm{g}$. The last tested temperature is $80^{\circ} \mathrm{C}$. All tests were repeated at this temperature, and their results are shown in Figure 2. The temperature increase has a positive effect on the absorption of the surfactant. Absorption density at this temperature at the final concentration of the surfactant is $3.37 \mathrm{mg} / \mathrm{g}$. Electrical conductivity and $\mathrm{pH}$ measurements were employed to obtain the critical concentration of the surfactant and polymer used in this study. In these methods, $\mathrm{pH}$ and electrical conductivity of different concentrations of the surfactant and polymer were measured and sketched versus concentration on a graph. The data drawn on the graph have two different trends. The trends were first regretted linearly using the linear method. Then, the critical concentration of the solutions corresponding to the intersection of the two lines was obtained. In this research, the critical concentrations of the surfactant and polymer were found to be $450 \mathrm{ppm}$ and 1300 ppm, respectively.

3.2. Hydrolyzed Polyacrylamide Addition Impact. In order to investigate the hydrolyzed polyacrylamide impact on the surfactant adsorption, 1300 ppm of this polymer was added to the surfactant solution with a concentration of $450 \mathrm{ppm}$. The obtained solution was placed on a magnetic stirrer at ambient temperature for 24 hours. It was then kept at room 

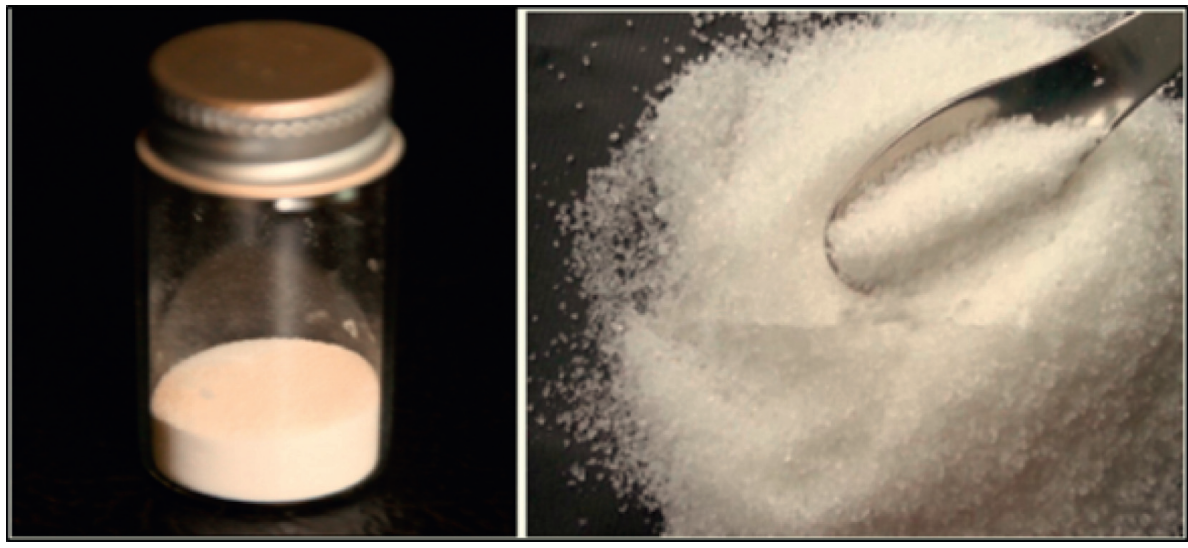

Figure 1: Hydrolyzed polyacrylamide.

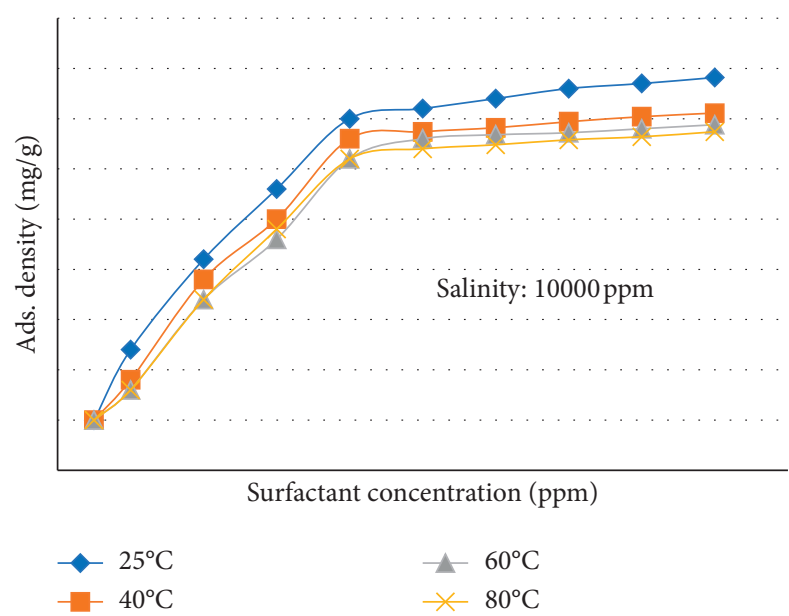

Figure 2: The surfactant adsorption density vs. Triton X-100 surfactant concentration at different temperatures and salt concentration of 10000 ppm.

TABLE 4: Initial and residual values of the surfactant/polymer at ambient temperature and $40^{\circ} \mathrm{C}$ with a concentration of $10000 \mathrm{ppm}$.

\begin{tabular}{lcccccc}
\hline $\begin{array}{l}\text { Test } \\
\text { no. }\end{array}$ & $\begin{array}{c}\text { Used } \\
\text { material }\end{array}$ & $\begin{array}{c}\text { Initial amount of } \\
\text { surfactant }+ \text { polymer } \\
(\mathrm{ppm})\end{array}$ & $\begin{array}{c}\text { Residual amount of } \\
\text { surfactant/polymer } \\
(\mathrm{ppm}) \text { at } 25^{\circ} \mathrm{C}\end{array}$ & $\begin{array}{c}\text { Adsorption density of } \\
\text { surfactant/polymer } \\
(\mathrm{mg} / \mathrm{g}) \text { at } 25^{\circ} \mathrm{C}\end{array}$ & $\begin{array}{c}\text { Residual amount of } \\
\text { surfactant/polymer } \\
(\mathrm{ppm}) \text { at } 40^{\circ} \mathrm{C}\end{array}$ & $\begin{array}{c}\text { Adsorption density of } \\
\text { surfactant/polymer } \\
(\mathrm{mg} / \mathrm{g}) \text { at } 40^{\circ} \mathrm{C}\end{array}$ \\
\hline 1 & $\mathrm{~S}$ & 450 & 285 & 3.30 & 297.60 & 3.048 \\
2 & $\mathrm{P}$ & 1300 & 1154 & 2.92 & 1167 & 765 \\
3 & $S+P$ & 875 & 757 & 2.36 & 2.660 \\
\hline
\end{tabular}

$\mathrm{S}$ : surfactant and $\mathrm{P}$ : polymer.

TABLE 5: Initial and residual values of the surfactant/polymer at $60^{\circ} \mathrm{C}$ and $80^{\circ} \mathrm{C}$ with a concentration of $10000 \mathrm{ppm}$.

\begin{tabular}{lcccccc}
\hline $\begin{array}{l}\text { Test } \\
\text { no. }\end{array}$ & $\begin{array}{c}\text { Used } \\
\text { material }\end{array}$ & $\begin{array}{c}\text { Initial amount of } \\
\text { surfactant + polymer } \\
(\mathrm{ppm})\end{array}$ & $\begin{array}{c}\text { Residual amount of } \\
\text { surfactant/polymer } \\
(\mathrm{ppm}) \text { at } 60^{\circ} \mathrm{C}\end{array}$ & $\begin{array}{c}\text { Adsorption density of } \\
\text { surfactant/polymer } \\
(\mathrm{mg} / \mathrm{g}) \text { at } 60^{\circ} \mathrm{C}\end{array}$ & $\begin{array}{c}\text { Residual amount of } \\
\text { surfactant/polymer } \\
(\mathrm{ppm}) \text { at } 80^{\circ} \mathrm{C}\end{array}$ & $\begin{array}{c}\text { Adsorption density of } \\
\text { surfactant/polymer } \\
(\mathrm{mg} / \mathrm{g}) \text { at } 80^{\circ} \mathrm{C}\end{array}$ \\
\hline $\mathbf{1}$ & $\mathrm{S}$ & 450 & 303.70 & 2.926 & 310 & 2.80 \\
$\mathbf{2}$ & $\mathrm{P}$ & 1300 & 1174 & 2.520 & 1186 & 2.28 \\
$\mathbf{3}$ & $S+P$ & 875 & 771 & 2.080 & 774 & 2.02 \\
\hline
\end{tabular}

$S$ : surfactant and $P$ : polymer. 

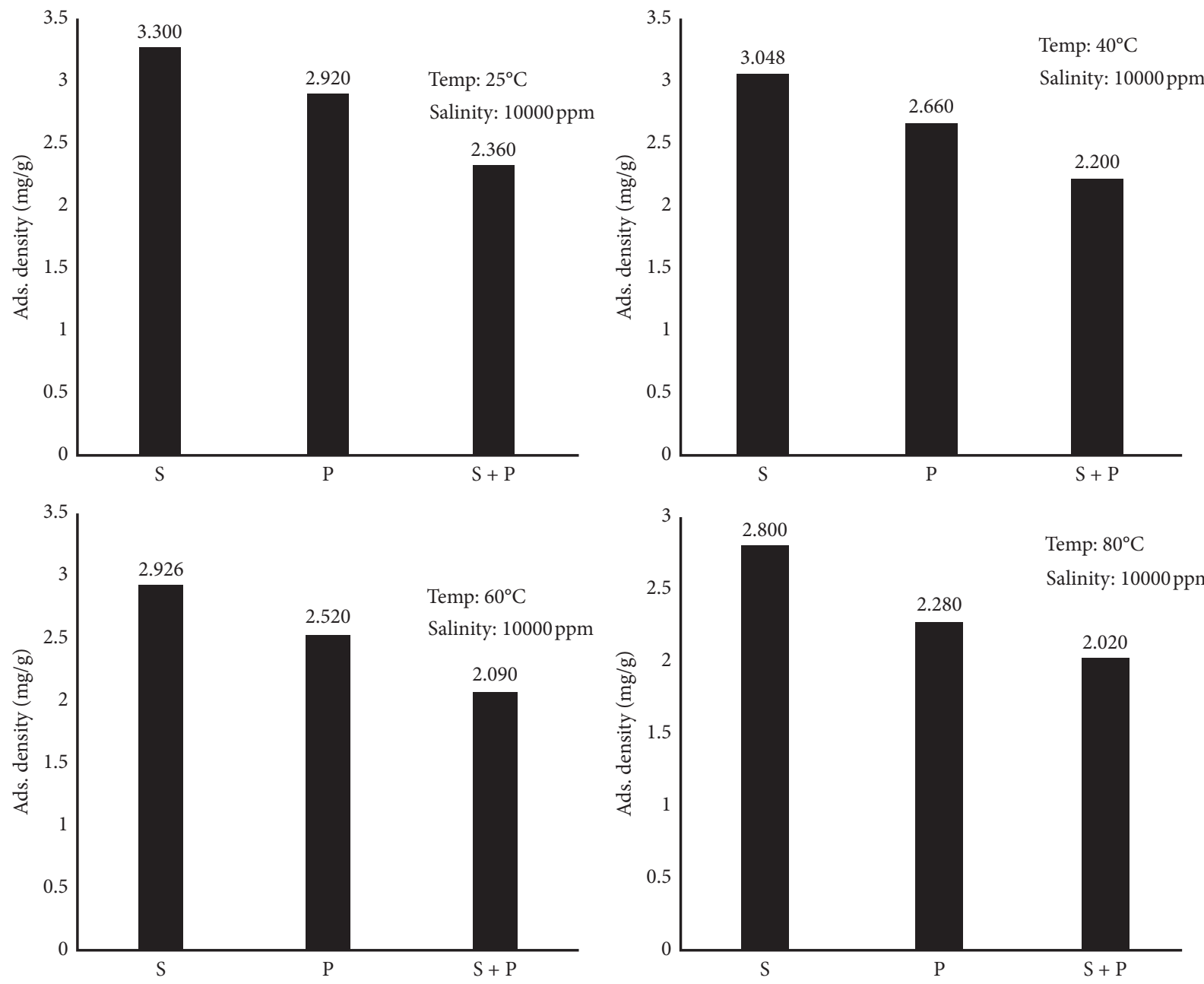

FIgURe 3: Polyacrylamide effect on the surfactant adsorption at different temperatures.

temperature for 12 hours to reach the equilibrium. After the equilibrium, some of the solutions were taken to measure the concentration of the surfactant by a spectrophotometer. The following tables and graphs show the results of these tests. It is concluded from the obtained data that the mixture of the polymer and surfactant could decrease the surfactant adsorption on the rock powder. Moreover, it could decrease the adsorption density from 3.3 to $2.92 \mathrm{mg} / \mathrm{g}$ at ambient temperature, 3.048 to $2.66 \mathrm{mg} / \mathrm{g}$ at $40^{\circ} \mathrm{C}, 2.926$ to $2.25 \mathrm{mg} / \mathrm{g}$ at $60^{\circ} \mathrm{C}$, and 2.8 to $2.28 \mathrm{mg} / \mathrm{g}$ at $80^{\circ} \mathrm{C}$. The results are shown in Tables 4 and 5 as well as in Figure 3.

\section{Conclusions}

The main findings of this study are as follows:

(i) The adsorption density of the surfactant or polymer reduced with increasing temperature. The maximum reduction in adsorption density was attained at $80^{\circ} \mathrm{C}$ for both additives.

(ii) The polymer was prepared in $1300 \mathrm{ppm}$ and added to the surfactant solution with $450 \mathrm{ppm}$. The results showed that hydrolyzed polyacrylamide had a positive effect on the reduction of the surfactant adsorption.

(iii) The adsorption rate of Triton X-100 and/or hydrolyzed polyacrylamide alone on carbonate rock was higher than that of both compounds in a mixture of 0.027 gr surfactant and 0.078 gr polymer.

(iv) As the temperature rises from $25^{\circ} \mathrm{C}$ to $80^{\circ} \mathrm{C}$, the rate of adsorption of the surfactant and polymer on the carbonate rock surface decreases, and this trend is likely to continue at temperatures above $80^{\circ} \mathrm{C}$; therefore, using of these compounds as a mixture (Triton X-100 and polyacrylamide) in oil reservoirs with a high temperature gradient (i.e., more than or equal to $80^{\circ} \mathrm{C}$ ) would be suitable in terms of the economic view.

(v) The adsorption density increases with increasing surfactant concentration up to CMC at a constant temperature, and then, it remained approximately stable.

In addition, different type probabilistic methods can be used to deal with objective uncertainties such as but not limited to [45-51]. 


\section{Data Availability}

The data used to support the findings of this study are available from the corresponding author upon request.

\section{Conflicts of Interest}

The authors declare that they have no conflicts of interest.

\section{Acknowledgments}

The authors are grateful to Shiraz University for supporting this research.

\section{References}

[1] H. Esfandyari, A. Haghighat Hoseini, S. R. Shadizadeh, and A. Davarpanah, "Simultaneous evaluation of capillary pressure and wettability alteration based on the USBM and imbibition tests on carbonate minerals," Journal of Petroleum Science and Engineering, 2020.

[2] X. Hu, J. Xie, W. Cai, R. Wang, and A. Davarpanah, "Thermodynamic effects of cycling carbon dioxide injectivity in shale reservoirs," Journal of Petroleum Science and Engineering, vol. 195, Article ID 107717, 2020.

[3] A. Davarpanah and B. Mirshekari, "Experimental investigation and mathematical modeling of gas diffusivity by carbon dioxide and methane kinetic adsorption," Industrial and Engineering Chemistry, vol. 58, no. 27, pp. 12392-12400, 2019.

[4] A. Davarpanah, "Parametric study of polymer-nanoparticlesassisted injectivity performance for axisymmetric two-phase flow in EOR processes," Nanomaterials, 2020.

[5] Y. Hu, Q. Cheng, J. Yang, L. Zhang, and A. Davarpanah, “A laboratory approach on the hybrid-enhanced oil recovery techniques with different saline brines in sandstone reservoirs," Processes, vol. 8, no. 9, 1051 pages, 2020.

[6] A. Davarpanah, "Feasible analysis of reusing flowback produced water in the operational performances of oil reservoirs," Environmental Science and Pollution Research, vol. 25, pp. 35387-35395, 2018.

[7] A. Davarpanah and B. Mirshekari, "Mathematical modeling of injectivity damage with oil droplets in the waste produced water re-injection of the linear flow," European Physical Journal - Plus, vol. 134, Article ID 12546, 2019.

[8] H. Esfandyari, S. R. Shadizadeh, F. Esmaeilzadeh, and A. Davarpanah, "Implications of anionic and natural surfactants to measure wettability alteration in EOR processes," Fuel, vol. 278, Article ID 118392, 2020.

[9] H. Esfandyari, A. Moghani Rahimi, F. Esmaeilzadeh, A. Davarpanah, and A. H. Mohammadi, "Amphoteric and cationic surfactants for enhancing oil recovery from carbonate oil reservoirs," Journal of Molecular Liquids, vol. 322, Article ID 114518, 2020.

[10] Z. Haiyan and A. Davarpanah, "Hybrid chemical enhanced oil recovery techniques: a simulation study," Symmetry (Basel), vol. 12, no. 7, Article ID 1086, 2020.

[11] F. Pan, Z. Zhang, X. Zhang, and A. Davarpanah, "Impact of anionic and cationic surfactants interfacial tension on the oil recovery enhancement," Powder Technology, vol. 373, pp. 93-98, 2020.

[12] M. Mazarei, A. Davarpanah, A. Ebadati, and B. Mirshekari, "The feasibility analysis of underground gas storage during an integration of improved condensate recovery processes,"
Journal of Petroleum Exploration and Production Technology, vol. 9, pp. 397-408, 2019.

[13] A. Davarpanah, R. Shirmohammadi, B. Mirshekari, and A. Aslani, "Analysis of hydraulic fracturing techniques: hybrid fuzzy approaches," Arabian Journal of Geosciences, vol. 12, no. 13, 402 pages, 2019.

[14] G. Houjian, X. Guiying, Z. Yanyan et al., "Influencing factors on the properties of complex systems consisting of hydrolyzed polyacrylamide/triton X-100/cetyl trimethylammonium bromide: viscosity and dynamic interfacial tension studies," Energy and Fuels, vol. 23, pp. 300-305, 2009.

[15] M. J. Rosen, H. Wang, P. Shen, and Y. Zhu, "Ultralow interfacial tension for enhanced oil recovery at very low surfactant concentrations," Langmuir, vol. 21, no. 9, pp. 3749-3756, 2005.

[16] A. Davarpanah, "A feasible visual investigation for associative foam $>\backslash$ polymer injectivity performances in the oil recovery enhancement," European Polymer Journal, vol. 105, pp. 405411, 2018.

[17] A. Davarpanah and B. Mirshekari, "Numerical simulation and laboratory evaluation of alkali-surfactant-polymer and foam flooding," International Journal of Environmental Science and Technology, vol. 17, pp. 1123-1136, 2020.

[18] S. Nesic, A. Zolotukhin, V. Mitrovic, D. Govedarica, and A. Davarpanah, "An analytical model to predict the effects of suspended solids in injected water on the oil displacement efficiency during waterflooding," Processes, vol. 8, p. 659, 2020.

[19] A. Davarpanah, R. Shirmohammadi, and B. Mirshekari, "Experimental evaluation of polymer-enhanced foam transportation on the foam stabilization in the porous media," International Journal of Environmental Science and Technology, vol. 16, pp. 8107-8116, 2019.

[20] Z. Zhao, Z. Li, W. Qiao, and L. Cheng, "Dynamic interfacial behavior between crude oil and octylmethylnaphthalene sulfonate surfactant flooding systems," Colloids and Surfaces A: Physicochemical and Engineering Aspects, vol. 259, no. 1, pp. 71-80, 2005.

[21] F. Li, L. Sun, Y. Wang, T. Wu, and Y. Li, "Effect of laponite particles on the emulsion stability of produced water from polymer flooding," Journal of Petroleum Science and Engineering, vol. 10, no. 1, pp. 49-61, 2014.

[22] A. Davarpanah, B. Mirshekari, T. Jafari Behbahani, and M. Hemmati, "Integrated production logging tools approach for convenient experimental individual layer permeability measurements in a multi-layered fractured reservoir," Journal of Petroleum Exploration and Production Technology, vol. 8, pp. 743-751, 2018.

[23] X. Hu, M. Li, C. Peng, and A. Davarpanah, "Hybrid thermalchemical enhanced oil recovery methods; an experimental study for tight reservoirs," Symmetry (Basel), vol. 12, no. 6, 947 pages, 2020.

[24] A. Davarpanah and B. Mirshekari, "Experimental study of $\mathrm{CO}_{2}$ solubility on the oil recovery enhancement of heavy oil reservoirs," Journal of Thermal Analysis and Calorimetry, vol. 139, 2019.

[25] A. Mandal, "Chemical flood enhanced oil recovery: a review," International Journal of Oil, Gas and Coal Technology, vol. 9, no. 3, 241 pages, 2015.

[26] S. M. Hosseini-Nasab, C. Padalkar, E. Battistutta, and P. L. J. Zitha, "Mechanistic modeling of the alkaline/surfactant/polymer flooding process under sub-optimum salinity conditions for enhanced oil recovery," Industrial and Engineering Chemistry, vol. 24, pp. 6875-6888, 2016. 
[27] X. Han, I. Kurnia, Z. Chen, J. Yu, and G. Zhang, "Effect of oil reactivity on salinity profile design during alkalinesurfactant-polymer flooding," Fuel, 2019.

[28] F. Li, L. Ye, Y. Li, and T. Wu, "Investigation into the adsorption of partially hydrolyzed polyacrylamide onto in situ formed magnesium hydroxide particles," RSC Advances, 2016.

[29] F. Li, W. He, D. Sun, T. Wu, and Y. Li, "Effect of sodiummontmorillonite particles on the stability of oil droplets in produced water from alkali/surfactant/polymer flooding," Journal of Cleaner Production, vol. 104, pp. 468-474, 2015.

[30] J. Guo, Q. Liu, M. Li, Z. Wu, and A. A. Christy, "The effect of alkali on crude oil/water interfacial properties and the stability of crude oil emulsions," Colloids and Surfaces A: Physicochemical and Engineering Aspects, vol. 273, pp. 213-218, 2006.

[31] A. Davarpanah and B. Mirshekari, "A simulation study to control the oil production rate of oil-rim reservoir under different injectivity scenarios," Energy Reports, vol. 4, pp. 664-670, 2018.

[32] L. Zhang, H. Xiao, H. Zhang, L. Xu, and D. Zhang, "Optimal design of a novel oil-water separator for raw oil produced from ASP flooding," Journal of Petroleum Science and Engineering, vol. 59, pp. 213-218, 2007.

[33] Z. Zhao, C. Bi, W. Qiao, Z. Li, and L. Cheng, "Dynamic interfacial tension behavior of the novel surfactant solutions and Daqing crude oil," Colloids and Surfaces A: Physicochemical and Engineering Aspects, vol. 294, pp. 191-202, 2007.

[34] C. Negin, S. Ali, and Q. Xie, "Most common surfactants employed in chemical enhanced oil recovery," Petroleum, vol. 3, pp. 197-211, 2017.

[35] P. Druetta, P. Raffa, and F. Picchioni, "Chemical enhanced oil recovery and the role of chemical product design," Applied Energy, vol. 252, Article ID 113480, 2019.

[36] X. Wu, M. Han, B. H. Zahrani, and L. Guo, "Effect of surfactant-polymer interaction on the interfacial properties for chemical EOR," SPE Middle East Oil Gas Show Conf MEOS, 2015.

[37] J. J. Sheng, "Modern chemical enhanced oil recovery," Modern Chemical Enhanced Oil Recovery, 2011.

[38] L. Cui, K. Ma, A. A Abdala et al., "Adsorption of a switchable cationic surfactant on natural carbonate minerals," $S P E$ Journal, 2015.

[39] M. V. Bennetzen, K. Mogensen, S. Frank, and K. Mohanty, "Dilute surfactant flooding studies in a low-permeability oilwet Middle East carbonate," in Social Petroleum Engineering International Peteroleum Technology Confeference 2014, IPTC 2014 Unlocking Energy through Innovative Technology Capability, Doha, Qatar, January 2014.

[40] S. S. Riswati, W. Bae, C. Park, A. K. Permadi, I. Efriza, and B. Min, "Experimental analysis to design optimum phase type and salinity gradient of Alkaline Surfactant Polymer flooding at low saline reservoir," Journal of Petroleum Exploration and Production Technology, vol. 173, pp. 1005-1019, 2019.

[41] J. Wang, M. Han, A. B. Fuseni, and D. Cao, "Surfactant adsorption in Surfactant-Polymer flooding for carbonate reservoirs," in Proceedings of the SPE Middle East Oil Gas Show Conference MEOS, Manama, Bahrain, March 2015.

[42] A. F. Belhaj, K. A. Elraies, M. S Alnarabiji et al., "Experimental investigation, binary modelling and artificial neural network prediction of surfactant adsorption for enhanced oil recovery application," Chemical Engineering Journal, vol. 406, Article ID 127081, 2021.

[43] S. Das, A. Katiyar, N. Rohilla, Q. Nguyen, and R. T. Bonnecaze, "Universal scaling of adsorption of nonionic surfactants on carbonates using cloud point temperatures,"
Journal of Colloid and Interface Science, vol. 577, pp. 431-440, 2020.

[44] R. Saha, R. V. S. Uppaluri, and P. Tiwari, "Effect of mineralogy on the adsorption characteristics of surfactant-reservoir rock system," Colloids and Surfaces A: Physicochemical and Engineering Aspects, vol. 531, pp. 121-132, 2017.

[45] S. Kabir, M. Yazdi, J. I. Aizpurua, and Y. Papadopoulos, "Uncertainty-Aware dynamic reliability analysis framework for complex systems," IEEE Access, vol. 6, pp. 29499-29515, 2018.

[46] M. Yazdi, "Introducing a heuristic approach to enhance the reliability of system safety assessment," Quality and Reliability Engineering International, pp. 1-27, 2019.

[47] M. Yazdi, "Footprint of knowledge acquisition improvement in failure diagnosis analysis," Quality and Reliability Engineering International, vol. 35, no. 1, pp. 405-422, 2018.

[48] M. Yazdi, "Ignorance-aware safety and reliability analysis: a heuristic approach," Quality and Reliability Engineering International, vol. 36, pp. 652-674, 2020.

[49] M. Yazdi, "A perceptual computing - based method to prioritize intervention actions in the probabilistic risk assessment techniques," Quality and Reliability Engineering International, pp. 1-27, 2019.

[50] M. Yazdi, S. Kabir, and M. Walker, "Uncertainty handling in fault tree based risk assessment: state of the art and future perspectives," Process Safety and Environmental Protection, vol. 131, pp. 89-104, 2019.

[51] S. Kabir, T. K. Geok, M. Kumar, M. Yazdi, and F. Hossain, "A method for temporal fault tree analysis using intuitionistic fuzzy set and expert elicitation," IEEE Access, vol. 8, pp. 980-996, 2020. 